Article

\title{
An Accurate and Efficient Fitness-For-Service Assessment Method of Pipes with Defects under Surface Load
}

\author{
Jianping Liu ${ }^{1}$, Hong Zhang ${ }^{1}$, Baodong Wang ${ }^{1}$, Dong Zhang ${ }^{1}$, Beilei $\mathrm{Ji}^{1}{ }^{1}$, Fan Fei ${ }^{2}$ and Xiaoben Liu ${ }^{1, *(1)}$ \\ 1 National Engineering Laboratory for Pipeline Safety, Beijing Key Laboratory of Urban Oil and Gas \\ Distribution Technology, China University of Petroleum-Beijing, Beijing 102249, China; \\ 2017314035@student.cup.edu.cn (J.L.); hzhang@cup.edu.cn (H.Z.); 2017314036@student.cup.edu.cn (B.W.); \\ 2017010862@student.cup.edu.cn (D.Z.); 2019215388@student.cup.edu.cn (B.J.) \\ 2 PipeChina, Beijing Natural Gas Pipeline Co., Ltd., Beijing 100013, China; fanfei@petrochina.com.cn \\ * Correspondence: xiaobenliu@cup.edu.cn; Tel.: +86-158-1055-6969
}

check for updates

Citation: Liu, J.; Zhang, H.; Wang, B.; Zhang, D.; Ji, B.; Fei, F.; Liu, X. An Accurate and Efficient Fitness-For-Service Assessment Method of Pipes with Defects under Surface Load. Energies 2021, 14, 5521. https://doi.org/10.3390/en14175521

Academic Editor: Marcin Kamiński

Received: 31 July 2021

Accepted: 30 August 2021

Published: 3 September 2021

Publisher's Note: MDPI stays neutral with regard to jurisdictional claims in published maps and institutional affiliations.

Copyright: (c) 2021 by the authors. Licensee MDPI, Basel, Switzerland. This article is an open access article distributed under the terms and conditions of the Creative Commons Attribution (CC BY) license (https:/ / creativecommons.org/licenses/by/ $4.0 /)$.
Abstract: With continued urbanization in China, the construction of urban gas pipelines is increasing, and the safety of gas pipelines are also increasingly affected by urban development and the increased scope of buildings and roads. Pipes with defects are more likely to fail under the surface loads. In this study, uniaxial tensile tests of high-density polyethylene (HDPE) pipes were carried out to obtain the real material parameters of pipe. A pipeline-soil interaction finite element model of HDPE pipeline with defects under surface load was established. The failure mechanism of the urban gas pipeline was studied and the influence of parameters such as internal pressure, defect position, defect depth on the mechanical behavior, and failure of pipelines were analyzed. A failure criterion for HDPE pipes with defects under surface load was proposed based on the limit-state curves obtained under different working conditions. Furthermore, an accurate and efficient fitness-for-service assessment procedure of pipes with defects under surface load was proposed. The results showed that maximum Mises stress of the pipeline gradually increased with increasing surface load and the position of maximum stress changed from the top and bottom of the pipe to the defect position and both sides of the pipe. Finally, when Mises stress of the HDPE pipe exceeds the yield limit, failure will occur. Internal pressure, defect location, and defect depth were found to influence the failure process and critical surface load of the pipeline. Safety evaluation curves of the gas pipeline with defects under surface load were obtained by calculating the critical failure load of the pipeline under various working conditions. Finally, a nonlinear fitting method was used to derive a formula for calculating the critical surface load under different defect parameters. The proposed method provides a useful reference for urban gas pipeline safety management.

Keywords: surface load; polyethylene pipe; defect; failure load; safety evaluation curve

\section{Introduction}

Urban gas pipelines are often located in public areas and may be influenced by building load, vehicle load, and third-party excavation. Moreover, pipelines in unoccupied areas may be vulnerable to be loaded from new buildings or roads as a result of urban construction projects, which threaten the safe operation of existing urban gas pipelines, as shown in Figure 1. Foundation settlement and pipeline deformation caused by repeated loading not only affects safe operation of oil and gas pipelines, but also creates the hidden danger of serious accidents. Gas pipeline companies are unable to perform routine inspections and maintenance on pipelines located on privately occupied land; therefore, hidden dangers are not identified or dealt with in time. China national petroleum corporation (CNPC) recently released statistics on existing pipelines in 22 regions, which showed that there are 23,045 pipelines under illegal surface load since August 2004, among which 11,000 are within $5 \mathrm{~m}$ of pipelines [1]. The pipelines in Sichuan province are exposed to more than 4000 surface load hazards, among which factories, residential buildings, and roads are 
most prominent [2]. In March 2013, an urban pipeline in the Xiaguan district of Nanjing leaked due to the repeated heavy rolling loads of heavy construction vehicles, eventually resulting in rupture of the gas pipeline [3].

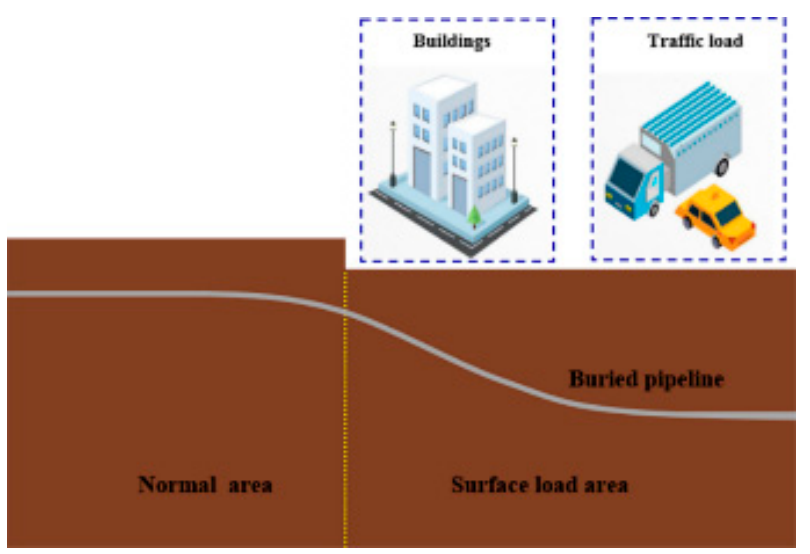

Figure 1. Schematic illustration of urban gas pipeline under surface load.

Trenchless pipe laying technology has become increasingly popular for gas pipelines. During construction, the pipeline is towed through a hole in the soil to complete the pipe-laying process. During the towing process, the walls of polyethylene pipelines are susceptible to scratch defects, as shown in Figure 2. In addition, weld quality may be inconsistent along the weld seam of pipes due to errors in the welding process, resulting in weld defects [4]. When the surface load acts on a pipeline with defect, the presence of defects increases the risk of pipeline failure. Therefore, studies on the failure mechanism and influencing factors of gas pipelines with defects under surface load are much needed to provide a reference for urban gas pipeline safety management.

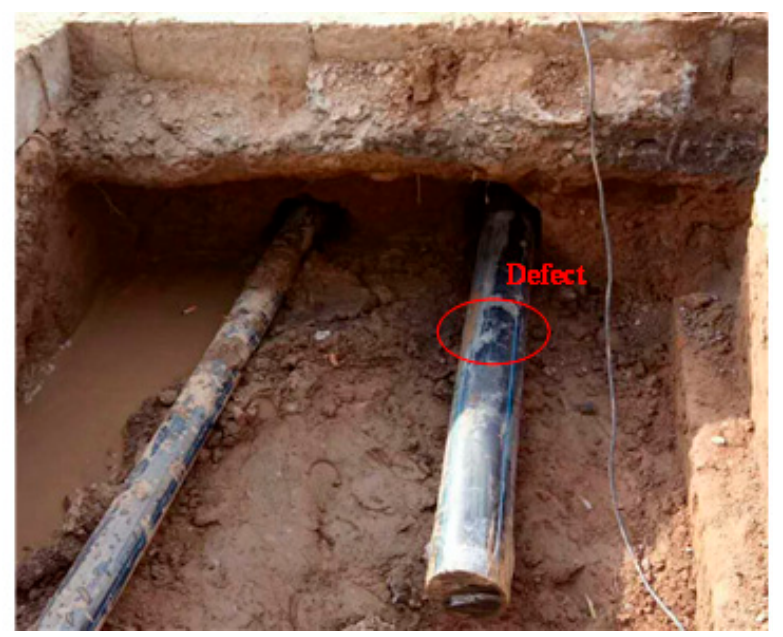

Figure 2. Image of pipe defect during trenchless construction of polyethylene pipeline.

Many scholars have investigated the mechanical behavior of pipelines under surface load. Shuai et al. [5] analyzed the stress and deformation of buried pipelines subjected to surface loads using the finite element analysis software ABAQUS. Sun [6] proposed a theoretical method for calculating the shear force, deformation, and bending moment of pipelines adjacent to buildings on a Winkler elastic foundation according to shortbeam theory. Han et al. [7] built a three-dimensional (3D) numerical model of a pipelinefoundation system and analyzed the influence of surface load on stress-strain characteristics of pipelines buried in hard rock regions. Zhang et al. [8] investigated pipeline deformation and stress-strain characteristics caused by rock fall impact. Zheng et al. [9] established 
a finite element model based on a constitutive model of PE and studied the influence of surface load parameters on a buried PE pipeline.

Yang [10] analyzed the mechanical characteristics of buried pipelines under long-term evenly distributed loads and impulsive loads. Ma et al. [11] established a 3D numerical model of a pipeline subjected to various loads to study the deformation and mechanical behavior of the pipeline. Han et al. [12] presented a 3D numerical model of pipeline-soil interaction. The influence of surface load, load action area, pipeline inner pressure, and elastic modulus of backfill soil on the stress and strain distributions in the pipeline were analyzed. Noor et al. [13] established a finite element model of a buried pipeline under vertical surface load in ANSYS. Trickey et al. Ref. [14] studied the impact of periodic ground loads on pipelines using the 3D finite element method. The impact of ground loads on pipelines of various material stiffness and buried depths were analyzed. Xiao et al. [15] established a stress model of a beam on an elastic foundation under random traffic loads to analytically determine the displacement response of a pipeline.

Recent research in this area has been mainly focused on intact pipelines, whereas few studies have investigated the mechanical behavior of pipelines with defects under surface load. Moreover, most studies have mainly considered metal pipelines, while studies on HDPE pipelines with defects are lacking. Gas pipelines are susceptible to defects during laying, installation, and welding processes; therefore, it is necessary to study the potential failure mechanism and limit states of HDPE pipelines with defects under surface load. The fitnessfor-service assessment of defective pipelines is a quantitative evaluation of whether the defective pipelines are suitable for continuous use and how to continue to use. The failure behavior of HDPE pipelines with defects under surface load were investigated in this paper. The influence of various pipeline defect parameters on the failure load were analyzed. In addition, safety evaluation curves for pipelines under surface load were obtained. This paper provides an important reference for urban gas pipeline safety management.

\section{Numerical Model of Pipe with Defect under Surface Load}

During service, the buried pipelines not only bear the weight of overlying soil, but also additional loads, such as buildings and vehicles acting on the ground. These additional loads can lead to uneven radial deformation of the pipeline. Defects in pipelines can result in stress concentrations at the defect position, which can easily lead to failure or rupture of the pipeline.

In order to accurately characterize the behavior of urban gas pipelines, a 3D pipe-soil interaction model of the HDPE pipeline with defects under surface load was established by finite element method, as shown in Figure 3. The model is comprised of two separate parts, the pipeline and the soil. A uniformly distributed static load was applied the ground and acted on the pipe through the foundation soil. Only half of the foundation structure was considered by assuming symmetry of the applied load. A rectangular area of $1.6 \mathrm{~m} \times 2 \mathrm{~m}$ was calculated as the surface load range of the model (red area in Figure 3). The dimensions of the finite element model were $10 \mathrm{~m} \times 4 \mathrm{~m} \times 2.4 \mathrm{~m}$ (length $\times$ width $\times$ height) and the buried depth of the pipeline was $0.8 \mathrm{~m}$.

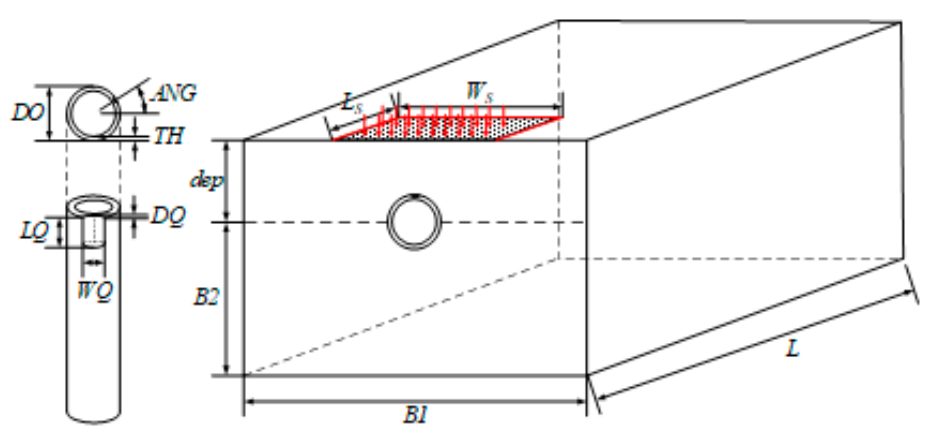

Figure 3. Schematic drawing of finite element model of pipeline with defects under surface load. 


\subsection{HDPE Pipe and Soil Properties}

The material properties test was carried out using an electronic universal testing machine. The tensile test specimens were directly cut from the HDPE pipeline according to standard ISO527-2012 [16], the size of test specimens are shown as Figure 4. Tensile tests were performed by controlling the displacement, and the loading rate was $50 \mathrm{~mm} / \mathrm{min}$, as shown in Figure 5 . The load-displacement relationship of HDPE can be recorded by test machine.

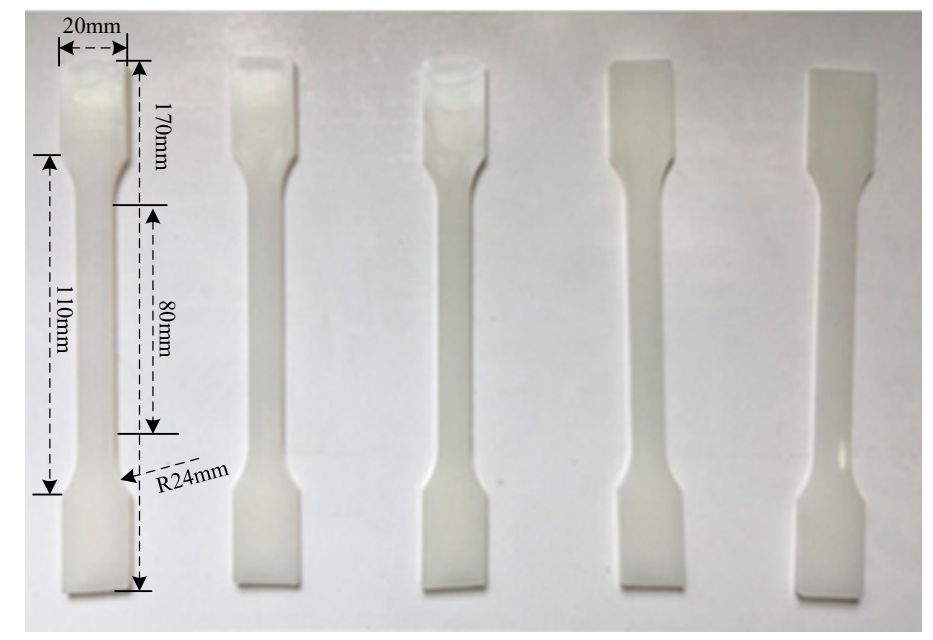

Figure 4. Image of tensile test specimens.

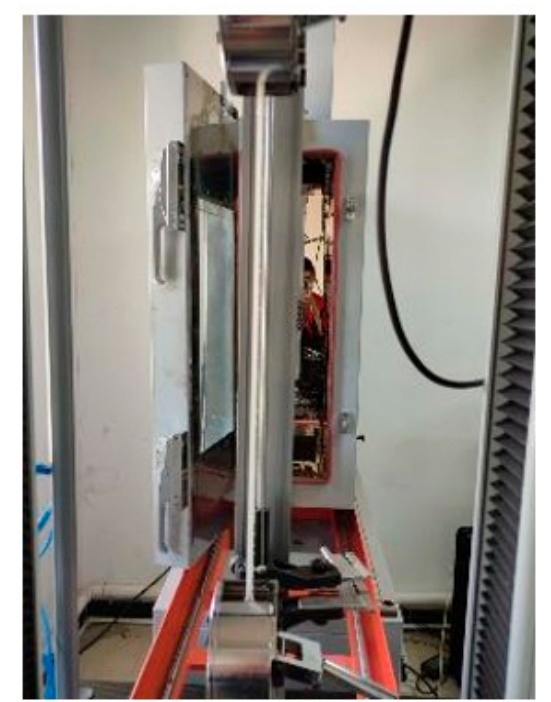

Figure 5. Image of tensile test apparatus.

In contrast to metal, HDPE is a nonlinear viscoelastic material that is more sensitive to strain rate and its material properties are highly influenced by loading rate [17]. The surface load acting on the pipe is equivalent to a quasi-static load, and the stress-strain curve of HDPE pipe was obtained by material uniaxial static tensile tests as shown in Figure 6. A hyperbolic constitutive model was used to simulate the material properties of the HDPE pipeline. By fitting Equation (1) to the real stress-strain curve, the parameters of the equation were obtained as 0.00089 and 0.057. According to ISO527-2012, the elastic modulus measured by uniaxial tensile test is the slope of the stress-strain curve in the strain range of $0.05 \%$ and $0.25 \%$. The HDPE parameters are listed in Table 1.

$$
\sigma=\frac{\varepsilon}{a+b \varepsilon}
$$


Here $\sigma$ is the true stress, MPa; $\varepsilon$ is the true strain; $a$ and $b$ are parameters of Equation (1) fitted true stress-strain curve.

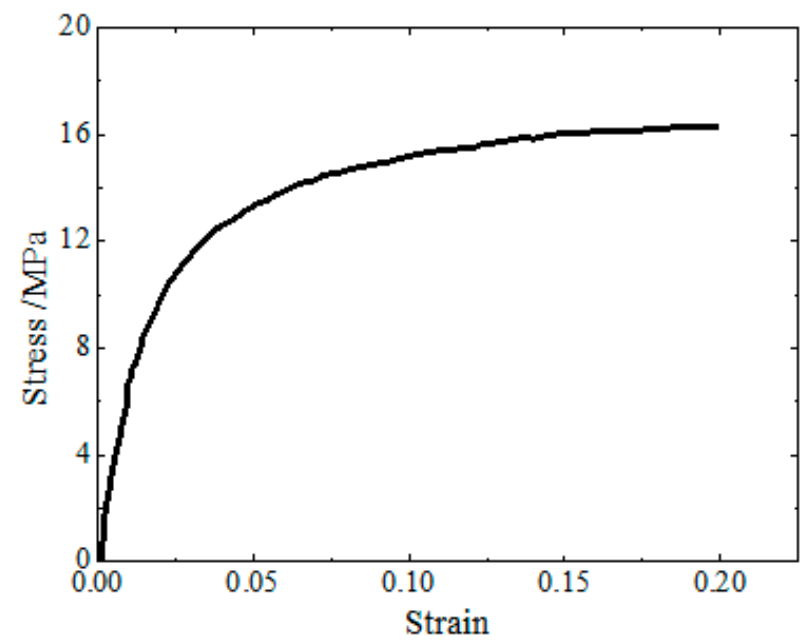

Figure 6. Stress-Strain curve of HDPE pipe.

Table 1. Material parameters of HDPE pipe.

\begin{tabular}{cccc}
\hline $\begin{array}{c}\text { Poisson Ratio } \\
\lambda\end{array}$ & $\begin{array}{c}\text { Density } \\
\rho / \mathbf{k g} \cdot \mathbf{m}^{-3}\end{array}$ & $\begin{array}{c}\text { Elastic Modulus } \\
\text { E/MPa }\end{array}$ & $\begin{array}{c}\text { Yield Stress } \\
\sigma_{s} / \mathbf{M P a}\end{array}$ \\
\hline 0.45 & 951 & 1115 & 14.5 \\
\hline
\end{tabular}

Considering the small deformation of soil, an elastoplastic constitutive model was adopted. Soil behaves according to the Mohr-Coulomb model, which is used in geotechnical engineering for materials under monotone loading [18]. The soil parameters are listed in Table 2.

Table 2. Parameters of Mohr-Coulomb model of small soil deformation.

\begin{tabular}{cccccc}
\hline $\begin{array}{c}\text { Poisson Ratio } \\
\lambda\end{array}$ & $\begin{array}{c}\text { Density } \\
\boldsymbol{\rho} / \mathbf{k g} \cdot \mathbf{m}^{-3}\end{array}$ & $\begin{array}{c}\text { Elastic Modulus } \\
\text { E/MPa }\end{array}$ & $\begin{array}{c}\text { Soil Cohesion } \\
\mathbf{C} / \mathbf{k P a}\end{array}$ & $\begin{array}{c}\text { Internal Friction } \\
\text { Angle } \\
\beta /{ }^{\circ}\end{array}$ & $\begin{array}{c}\text { Dilatancy } \\
\text { Angle } \\
\psi{ }^{\circ}\end{array}$ \\
\hline 0.4 & 1867.3 & 20 & 29.3 & 28.7 & 0 \\
\hline
\end{tabular}

\subsection{Mesh and Boundary Conditions of Finite Element Model}

To accurately simulate pipe-soil interaction, a solid model of the pipeline with defects under surface load was established. The pipe is made of HDPE with a diameter of $110 \mathrm{~mm}$, a wall thickness of $10 \mathrm{~mm}$, and an internal pressure of $0.2 \mathrm{MPa}$. The pipe defect was modeled as an axial groove and the position, depth, width, and length of the defect were varied [19]. Eight-node hexahedral elements SOILD45 were used to simulate the pipeline, as shown as Figure 7. TARGE170 element and CONTACT173 element were selected to analyze the pipeline-soil deformation process. The penalty function was used to calculate and analyze the friction between pipeline and soil. The penalty stiffness was 0.1. In our previous work, a series of mesh convergence studies were performed to determine a suitable mesh with an appropriate balance between accuracy and computational time. 


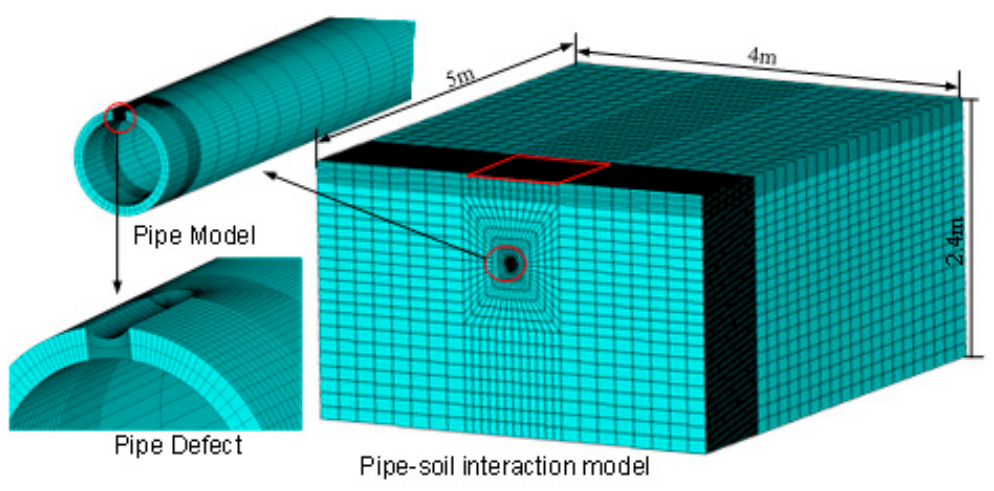

Figure 7. Finite element model of pipe-soil interaction.

Dimensionless parameters can be introduced to simulate the defect size parameters, including defect length $L(\mathrm{~mm})$, width $W(\mathrm{~mm})$, and depth $D(\mathrm{~mm})$ [20]. The three parameters can be determined as follows:

$$
\left\{\begin{array}{l}
L=\sqrt{n D t} \\
W=2 D \sin \frac{\theta}{2} \\
D=\mu t
\end{array}\right.
$$

where $D$ is the outer diameter of the pipe, $\mathrm{mm}$; $t$ is the pipe wall thickness, $\mathrm{mm} ; n$ is order of magnitude of the defect length, $\theta$ is the defect circumferential angle, and $\mu$ is the ratio of defect depth to wall thickness.

\subsection{Failure Criterion of HDPE Pipeline}

Typical failure modes of buried pipelines include strength failure, buckling, and excessive deformation. The failure modes of HDPE pipelines with defects under surface load are mainly related to excessive stress [21]. Failure of the pipeline occurs when the equivalent stress of the pipeline reaches the yield limit. Here, the fourth strength theory was used to calculate the equivalent stress. Then the critical state of the HDPE pipeline can be obtained as:

$$
\sigma_{s}=\sqrt{\frac{1}{2}\left[\left(\sigma_{1}-\sigma_{2}\right)^{2}+\left(\sigma_{1}-\sigma_{3}\right)^{2}+\left(\sigma_{2}-\sigma_{3}\right)^{2}\right]}
$$

where $\sigma_{s}$ is the maximum von Mises stress in the pipe, $\mathrm{MPa} ; \sigma_{1}, \sigma_{2}$, and $\sigma_{3}$ are the three principal stresses, $\mathrm{MPa}$.

\section{Validation of the Finite Element Model}

Scholars have previously studied the mechanical behavior of intact HDPE pipes under surface load. To verify the proposed method and the accuracy of the finite element model, an analysis model of an intact HDPE pipe with no defect under surface load was established. The simulation results were compared with Zheng's previously published results [16]. The variation of maximum Mises stress of the arch camber line of the pipe with surface load was analyzed, as shown in Figures 8 and 9. The results of the present study were consistent with those of previously published works, thus verifying the rationality of the model.

An axial groove defect was added to the intact pipe model in order to analyze the same HDPE pipe with a defect under surface load. The defect can be described using four geometric parameters: location $\mu$, depth $D$, length $L$, and width $W$. The failure mechanism of the pipe was analyzed by varying the geometric parameters of the defect. 


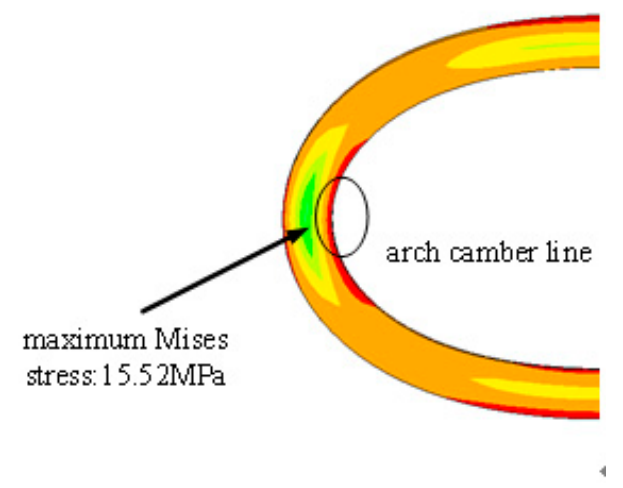

Figure 8. Maximum von Mises stress along the arch camber line in intact pipeline with no defect.

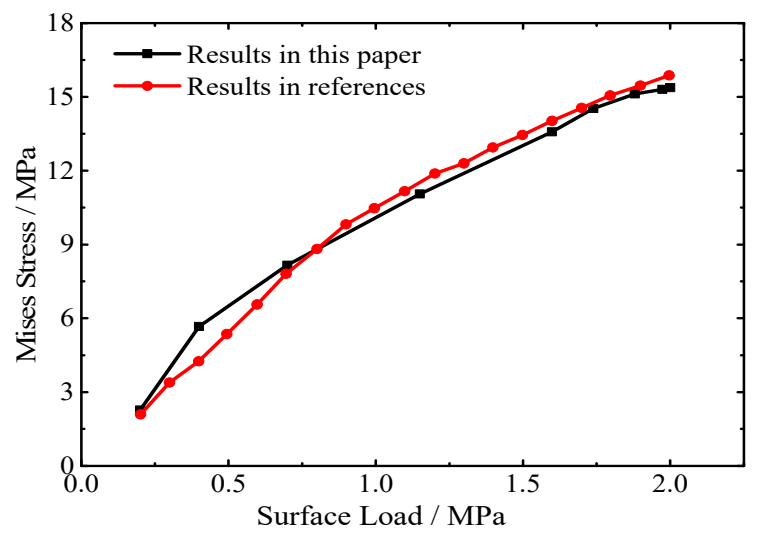

Figure 9. Variation of von Mises stress along arch camber line with load [16].

\section{Analysis of Finite Element Simulation Results}

\subsection{Failure Mechanism of Pipe with Defect under Surface Load}

In the practical engineering application, various types of defects can be found in pipelines [22]. The influence of geometric parameters of the defect on the failure process of HDPE pipelines was studied using the proposed finite element model. The geometric parameters were varied while other parameters were kept constant. The internal pressure was $0.2 \mathrm{MPa}$, the axial length of the defect was $50 \mathrm{~mm}$, the defect width was $15 \mathrm{~mm}$, and the defect depth was $4 \mathrm{~mm}$.

Figure 10 shows the variation of Mises stress and stress distribution during the failure process of the HDPE pipeline when the position of defect is $90^{\circ}$. The maximum Mises stress of the pipeline gradually increases with increasing surface load, the curve begins to flatten when the surface load becomes large. This is mainly because the bearing capacity of the pipe begins to decrease once the material enters the plastic deformation state; therefore, stress in the pipe will no longer significantly increase as the load increases. Moreover, the position of maximum Mises stress is not constant during the loading process, but gradually transfers from the top and bottom of pipeline to the defect position and the left and right sides of the pipeline. Finally, when the surface load is $2.2 \mathrm{MPa}$, the maximum Mises stress at the defect site and the arch line of the pipeline exceeds the yield limit and the pipe fails. This is because the stiffness of the pipeline is not sufficient to support the load as the compressive load increases. During deformation, stress concentrations are generated at the defect position and the arch line, resulting in failure of the pipeline. 


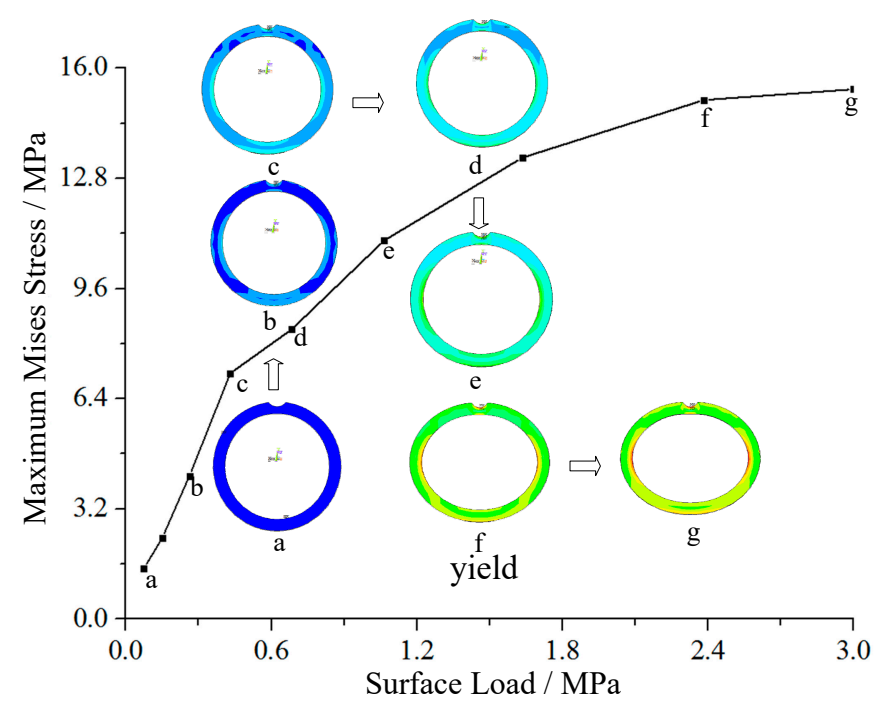

Figure 10. Failure process of HDPE pipe with defects under surface load.

\subsection{Parameter Analysis}

\subsubsection{Defect Location}

To analyze the influence of defect location on the pipeline failure process, defects at $0^{\circ}$, $30^{\circ}, 45^{\circ}, 60^{\circ}$, and $90^{\circ}$ on the pipeline were selected. Figure 11 shows the failure processes of the HDPE pipeline with defects at different positions. The maximum von Mises stress was obtained for a defect at $0^{\circ}$ and the minimum von Mises stress for a defect at $30^{\circ}$. The von Mises stresses were approximately equal at symmetrical defect positions with respect to the symmetric axis. When the defect position was between $30^{\circ}$ and $60^{\circ}$, the distribution of von Mises stresses in the pipeline were almost consistent.

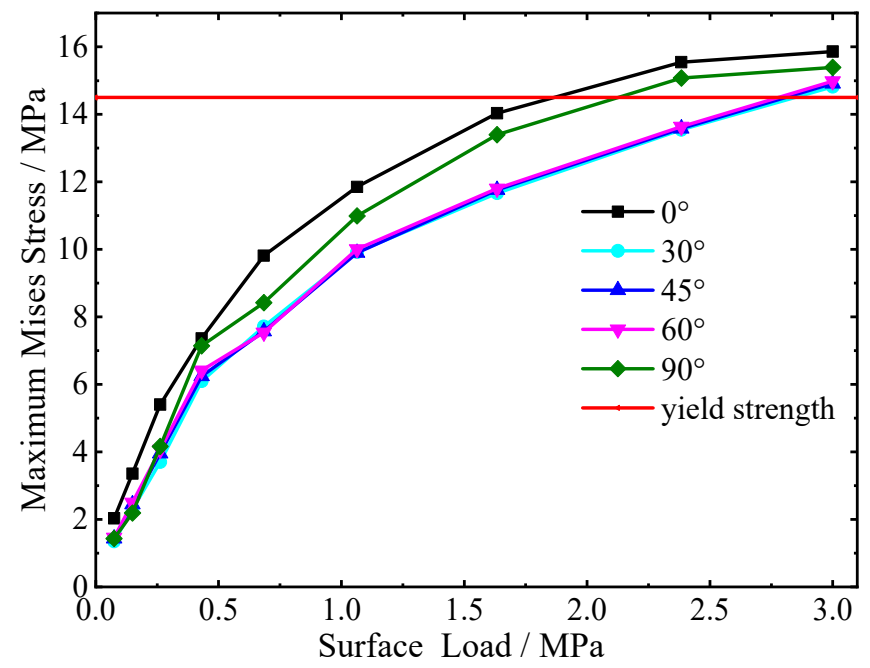

Figure 11. Maximum von Mises stress in HDPE pipeline with different defect locations.

The critical failure surface load and failure position of the HDPE pipeline were extracted for different defect positions, as shown in Figure 12. When the defect was at $0^{\circ}$, the critical failure load was smallest, with a value of $1.8 \mathrm{MPa}$. When the defect position was $30^{\circ}$, the critical failure load was $2.84 \mathrm{MPa}$. Moreover, when the defect position was between $0^{\circ}$ and $60^{\circ}$, the pipe failed at the arch line. When the defect position was between $60^{\circ}$ and $90^{\circ}$ (including $60^{\circ}$ ), the pipe failed at the defect and at the arch line. When the defect position is $0^{\circ}$, the pipeline was likely to fail under the surface load; therefore, all defects in the subsequent analysis were located at $0^{\circ}$. 


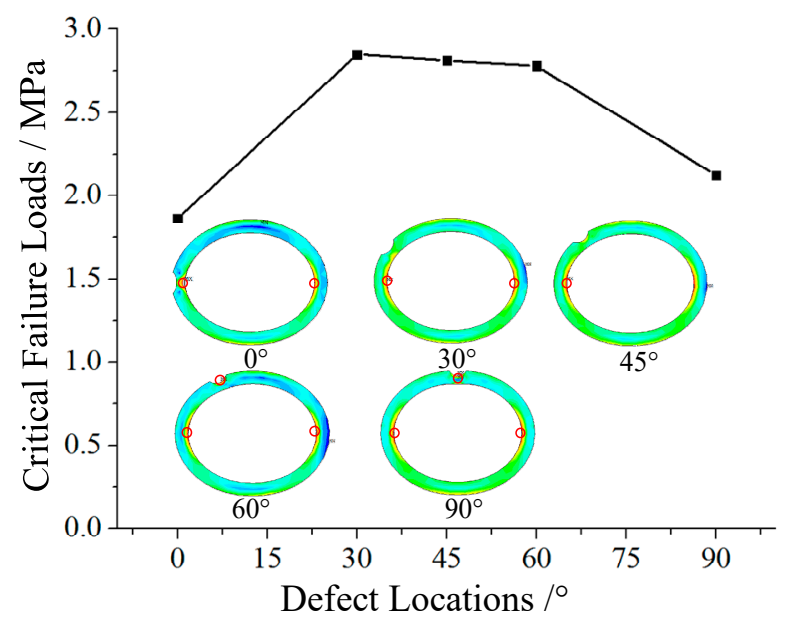

Figure 12. Critical failure load of the HDPE pipeline with various defect locations.

\subsubsection{Internal Pressure Load}

Urban gas pipelines typically operate at medium to sub-high pressures $(0.2-0.7 \mathrm{MPa})$. To analyze the influence of internal pressure on the failure behavior of the HDPE pipeline with defects under surface load, the mechanical performance of the pipeline with a defect depth of $4 \mathrm{~mm}$ was analyzed under various internal pressures, as shown in Figure 13.

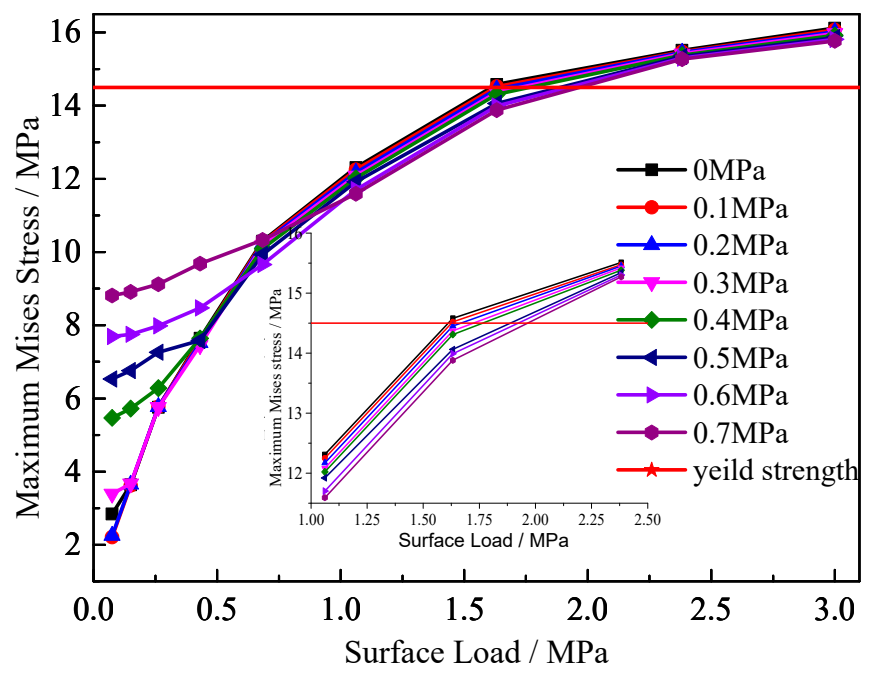

Figure 13. Maximum von Mises stress in HDPE pipe under different internal pressure loads.

Under small surface load, the pressure in the pipe had a major influence on the mechanical behavior of the pipe. When the surface load was less than $0.5 \mathrm{MPa}$, the maximum von Mises stress increased as the internal pressure load increased. When the surface load was large, the defect parameters had a more dominant influence on the mechanical properties of the pipe. The maximum von Mises stress of the pipe decreased as the internal pressure load increased. Once the maximum von Mises stress in the pipe exceeds the yield limit and expires, pressure in the pipe will have very little impact on the mechanical behavior of the pipe.

Figure 14 shows the distribution of the pipeline failure locations with internal pressure load. When the internal pressure of the pipeline is small, failure occurs on the inner wall of the arch camber line on both sides of the pipeline. When the internal pressure load is greater than $0.3 \mathrm{MPa}$, only the inner wall of the pipeline at the defect will fail and the failure area of the pipeline will decrease with increasing internal pressure load. When the 
internal pressure is $0.7 \mathrm{MPa}$, the pipeline failure area is concentrated along the inner wall of the defect.

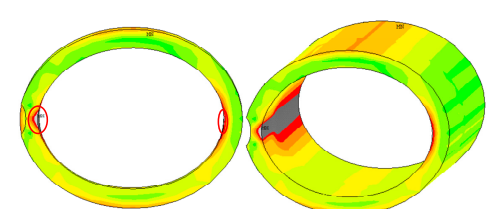

$0.1 \mathrm{MPa}$

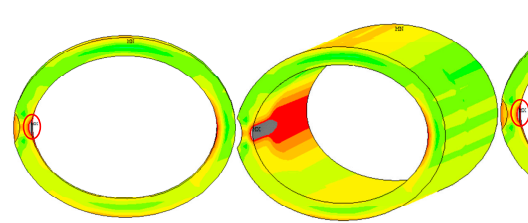

$0.5 \mathrm{MPa}$

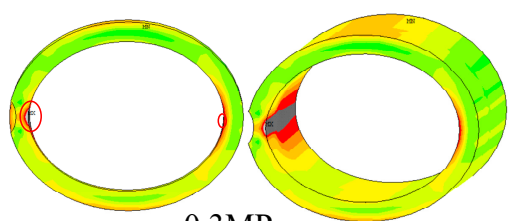

$0.3 \mathrm{MPa}$

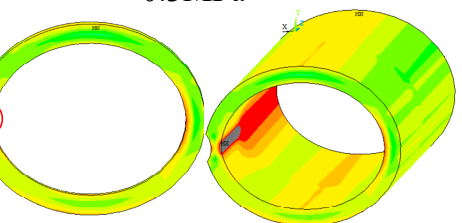

$0.7 \mathrm{MPa}$

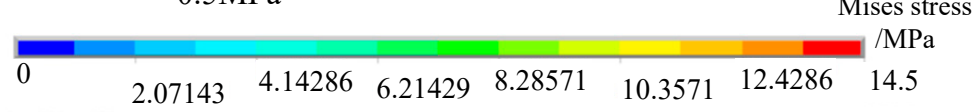

Figure 14. Location of HDPE pipeline failure with different internal pressures.

\subsubsection{Defect Depth}

Defects in HDPE pipes may have different depths. To study the influence of defect depth on the pipeline failure process, defect depth was varied and all other geometric parameters were kept unchanged. Figure 15 shows the failure process of the HDPE pipeline with various defect depths. The maximum von Mises stress in the HDPE pipeline gradually increased with increasing defect depth, and the variation trend was similar. The critical failure load was extracted for different defect depths, as shown in Figure 16. The relationship between defect depth and critical failure load was approximately linear. As the defect depth increased, the critical failure load of the pipeline gradually decreased. This is mainly because stress concentrations at the defect in the pipeline are more obvious as the defect depth increases; therefore, failure is more likely to occur.

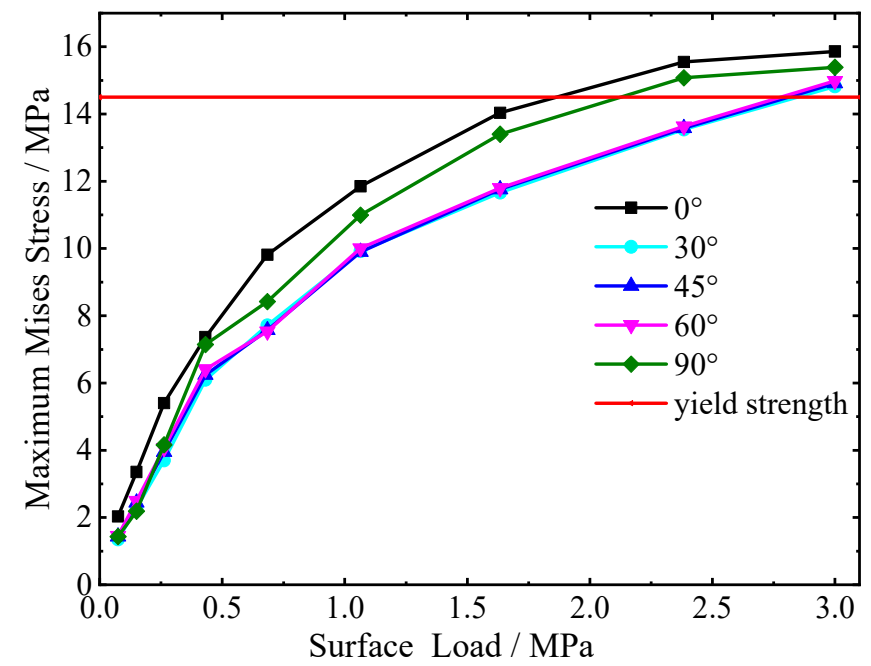

Figure 15. Maximum Mises stress in HDPE pipeline with various defect depths. 


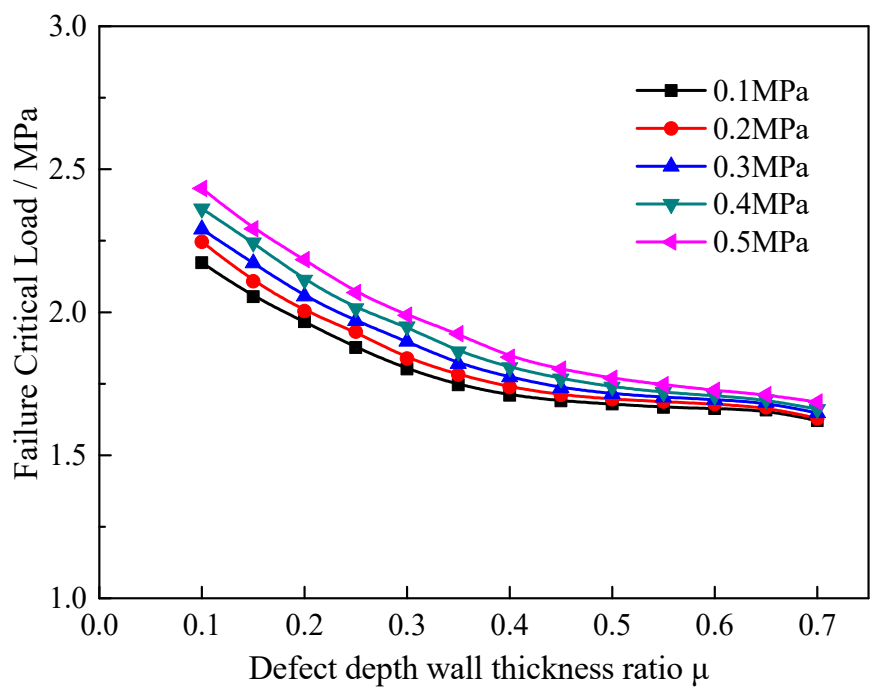

Figure 16. Critical failure load of HDPE pipeline for various defect depths.

Figure 17 shows the distribution of the position of pipeline failure with different defect depths. The positions of pipeline failure are located on the inner wall of the arch camber line on both sides. With increasing defect depth, the failure area of the inner wall at the defect location increases. When the defect depth is $5 \mathrm{~mm}$, half of the remaining thickness of the pipe defect location will fail and when the defect depth is increased to $7 \mathrm{~mm}$, the remaining thickness of the pipe defect location will fail basically.
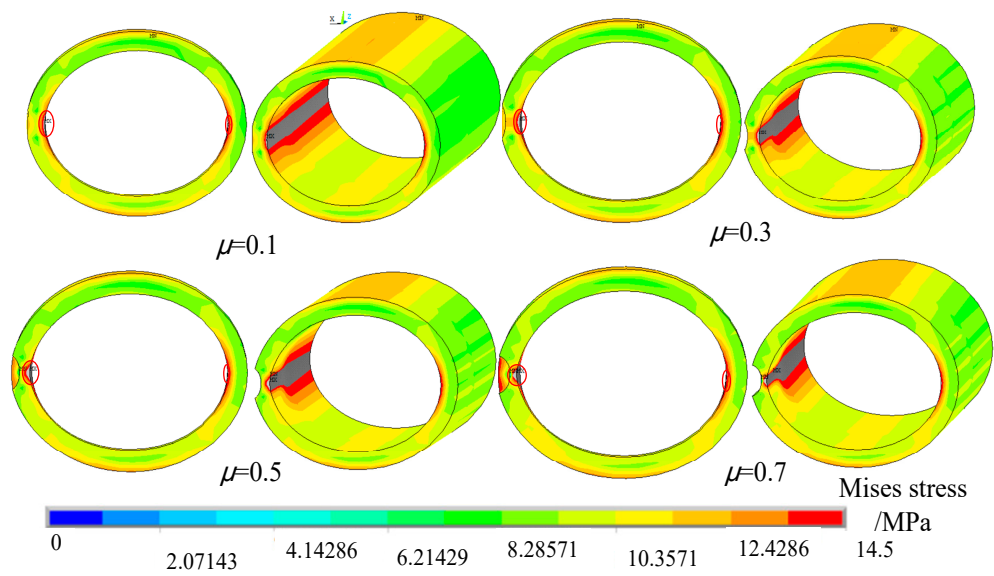

Figure 17. Location of HDPE pipeline failures with various defect depths.

\subsubsection{Defect Length}

The influence of defect length on the pipeline failure process was investigated. Figure 18 shows the HDPE pipeline failure process with different defect lengths. The maximum von Mises stress in the pipeline gradually increased with increasing defect length. When the defect length reached $30 \mathrm{~mm}$, the maximum Mises stress had almost no effect on the von Mises stress in the pipeline. The critical failure load of the pipeline with different defect lengths is shown in Figure 19. When the order of magnitude of the axial length of the pipeline was greater than 2 , the critical failure load of the pipeline tended to remain unchanged. 


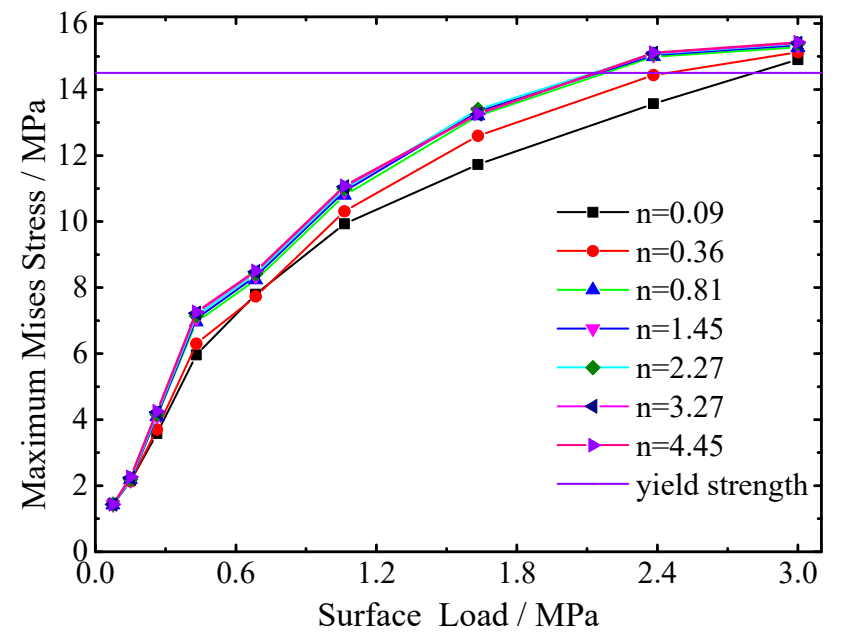

Figure 18. Maximum von Mises stress in HDPE pipeline with different defect lengths.

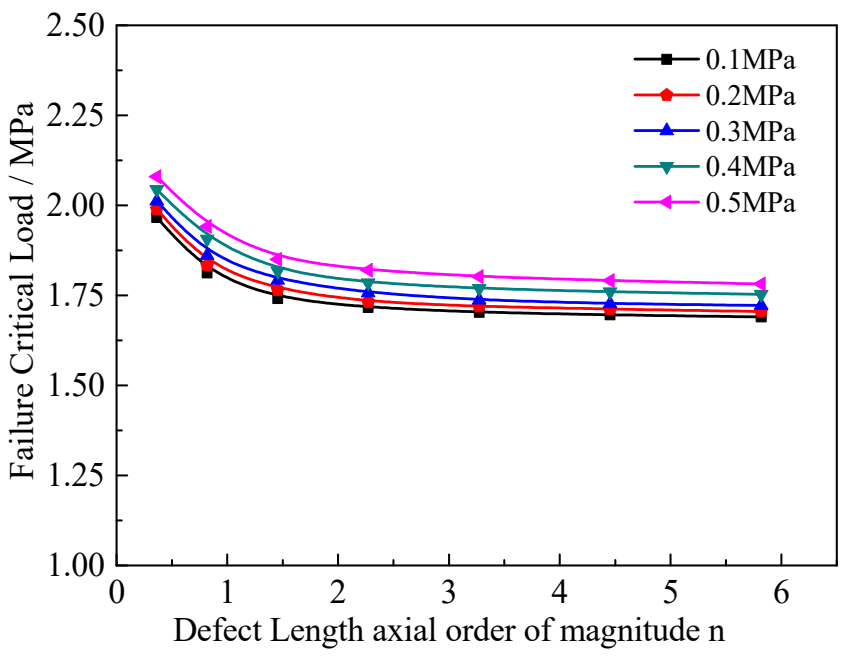

Figure 19. Critical failure load of HDPE pipe with different defect lengths.

Figure 20 shows the distribution of failure locations with defect length. Failures occurred on the inner walls of the arch camber lines on both sides of the pipe. Defect length had a relatively small impact on the location of pipeline failure.

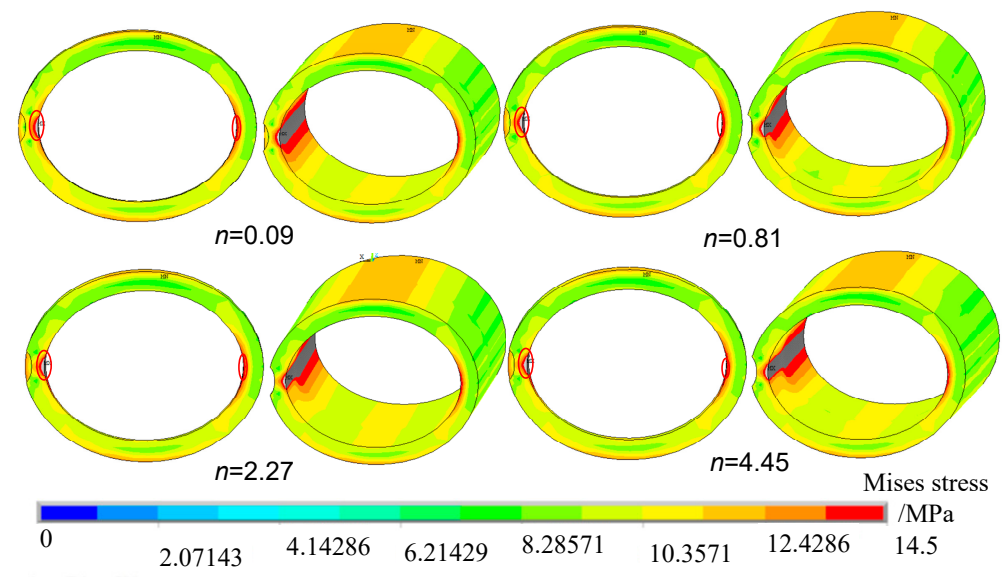

Figure 20. Location of HDPE pipeline failure with various defect lengths. 


\subsubsection{Defect Width}

Defect width is another important factor affecting the pipeline failure process. The maximum von Mises stress of the pipe with different defect widths was extracted, as shown in Figure 21. The von Mises stress in the HDPE pipe gradually decreased with increasing defect width. Critical failure loads of the pipeline with different defect widths are shown in Figure 22.

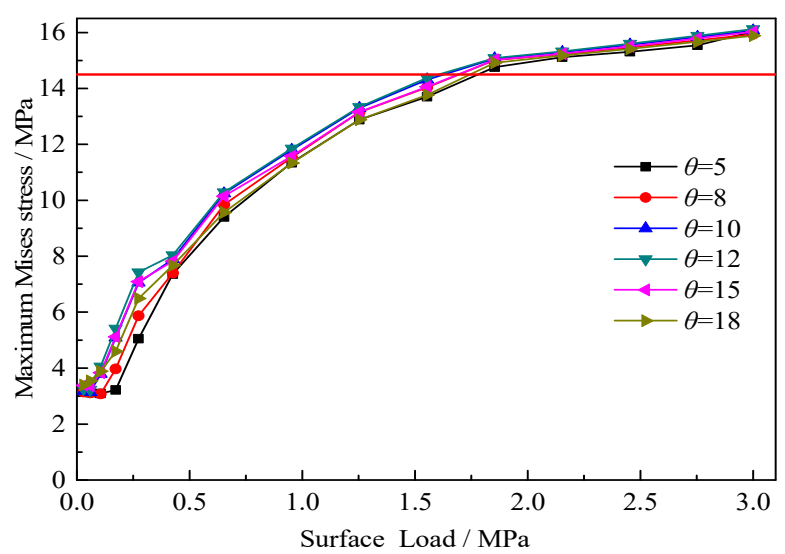

Figure 21. Maximum von Mises stress in HDPE pipe with various defect widths.

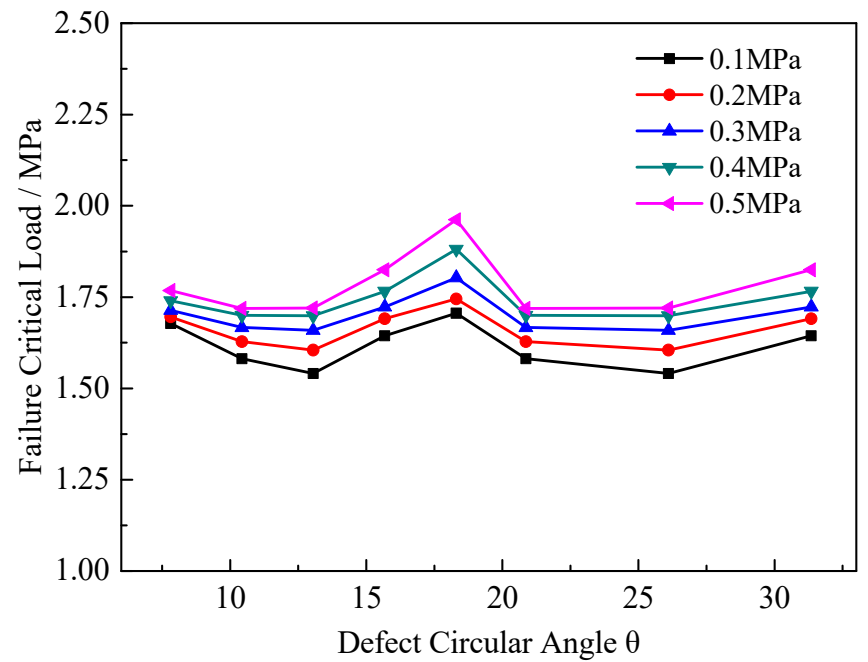

Figure 22. Critical failure load of HDPE pipe with various defect widths.

Figure 23 shows the distribution of pipeline failure position with defect width. The pipeline failure positions are located on the inner wall of the arch camber line on both sides of the pipe. As the defect width increased, the failure area on the inner wall of the pipeline at the defect position gradually increased. 


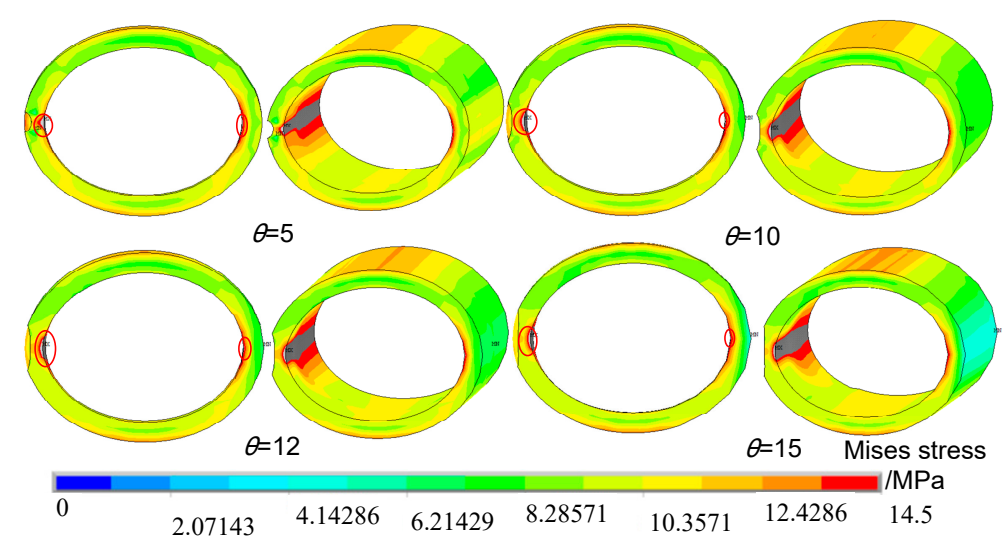

Figure 23. Location of HDPE pipeline failure with various defect widths.

\section{Fitness-for-Service Assessment Model Based on Failure Assessment Curves}

To obtain the ultimate load of the HDPE pipe with different defect depths, curves of defect depth versus critical surface load under different internal pressures were produced for defects at $0-30^{\circ}$, as shown in Figure 24. Internal pressure will affect the critical load of the pipe. The ultimate load increases with increasing pipeline internal pressure. Furthermore, the ultimate load decreases with increasing defect depth and the curve tends to flatten when defect depth $\mu$ is greater than 0.5 . Defect depth has a more obvious influence on the limit surface load when defect depth $\mu$ is less than 0.5 .

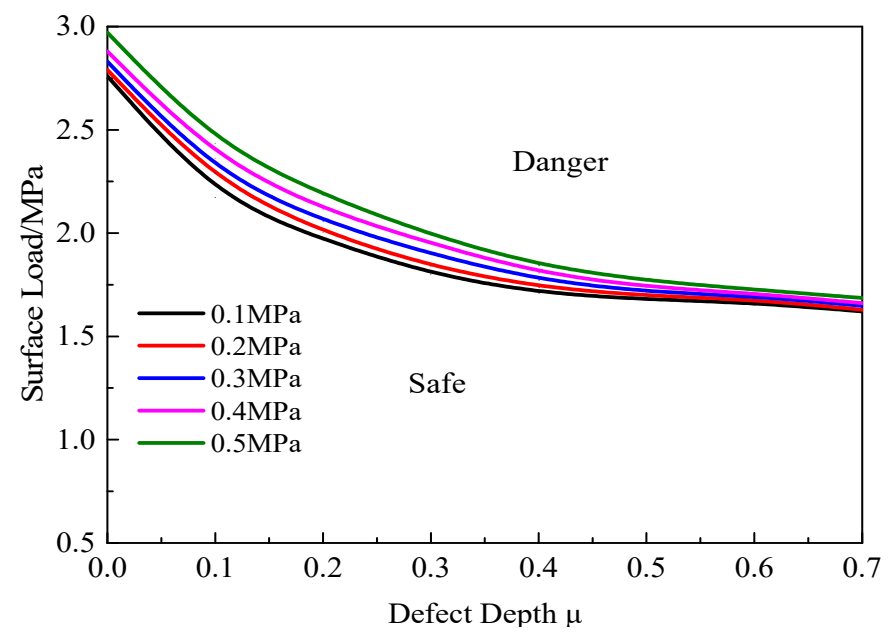

Figure 24. Defect depth-critical surface load curves under various internal pressure loads $\left(0-30^{\circ}\right)$.

Formulae for the ultimate surface load, defect depth, and internal pressure of the pipeline when a defect is located at $0-30^{\circ}$ of the pipeline can be obtained. The R-squared of the correlation coefficient is 0.990 , which indicates that the fitting formula reflects the data well.

$$
S L_{0 \sim 30^{\circ}}=\left(a_{1} \mu^{3}+a_{2} \mu^{2}+a_{3} \mu+a_{4}\right) \cdot\left(a_{5} P^{a_{6}}+a_{7}\right)
$$

Here $S L_{0 \sim 30^{\circ}}$ represents critical surface load when the defect is located at $0-30^{\circ}, \mathrm{MPa}$; $\mu$ represents the defect depth; $P$ represents internal pressure, $\mathrm{MPa} ; a_{1}, a_{2}, a_{3}, a_{4}, a_{5}, a_{6}$, and $a_{7}$ are the coefficients of the equation, as listed in Table 3.

Table 3. Coefficient of the fitting formula $\left(0-30^{\circ}\right)$.

\begin{tabular}{ccccccc}
\hline $\mathbf{a}_{\mathbf{1}}$ & $\mathbf{a}_{\mathbf{2}}$ & $\mathbf{a}_{\mathbf{3}}$ & $\mathbf{a}_{\mathbf{4}}$ & $\mathbf{a}_{\mathbf{5}}$ & $\mathbf{a}_{\mathbf{6}}$ & $\mathbf{a}_{\mathbf{7}}$ \\
\hline-2.005 & 3.960 & -2.782 & 1.858 & 0.309 & 1.233 & 1.353 \\
\hline
\end{tabular}


A comparison between the predicted results and simulation results with defects at $0-30^{\circ}$ is presented in Figure 25. The percentage difference was less than $10 \%$.

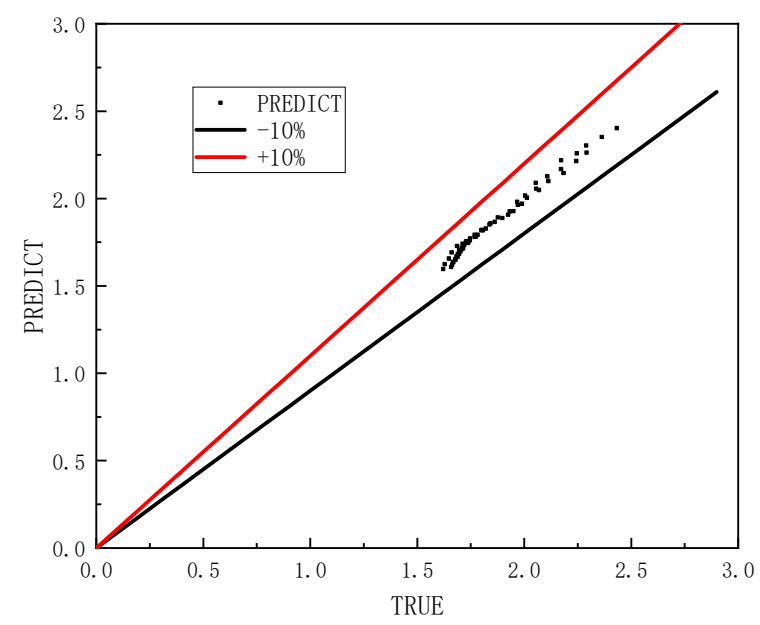

Figure 25. Comparison between predicted results and calculated results $\left(0-30^{\circ}\right)$.

When the defect was located at $30-60^{\circ}$, an equivalent analysis was carried out by the result of the defect located at $45^{\circ}$. The limit state of the pipeline is shown in Figure 26. When the defect was located at $30-60^{\circ}$, the critical failure load of the pipeline was significantly greater than those of pipelines with defects located at $0^{\circ}$ and $90^{\circ}$. When the defect depth is greater than 0.4 , defect depth will have a more significant impact on the critical failure load.

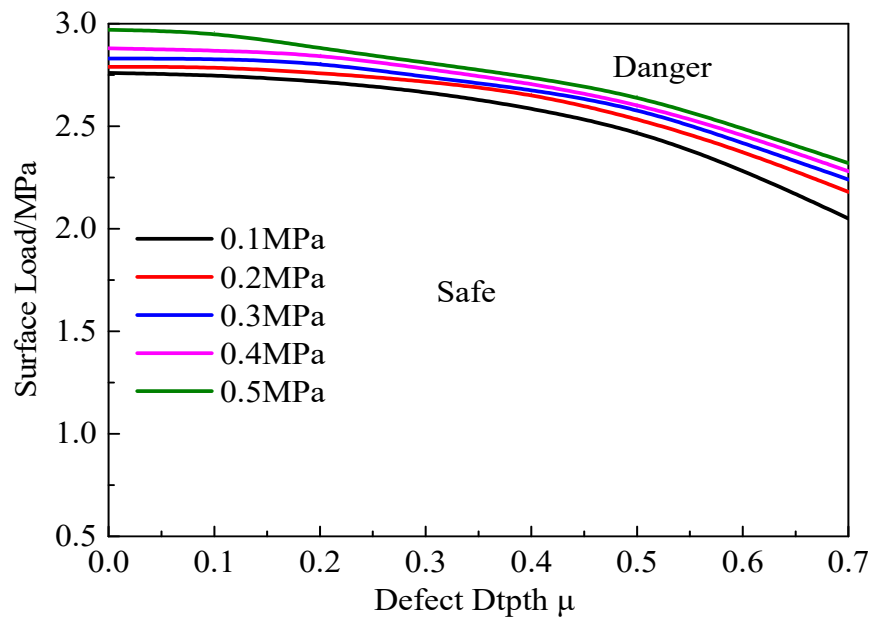

Figure 26. Defect depth-critical surface load curves under various internal pressure loads $\left(30 \sim 60^{\circ}\right)$.

Formulae for the ultimate surface load, defect depth, and internal pressure of the pipeline when the defect is located at $30-60^{\circ}$ were obtained according to the failure evaluation curves. The R-squared of the correlation coefficient is 0.990 .

$$
S L_{30 \sim 60^{\circ}}=\left(a_{1} \mu^{3}+a_{2} \mu^{2}+a_{3} \mu+a_{4}\right) \cdot\left(a_{5} P^{a_{6}}+a_{7}\right)
$$

Here $S L_{30 \sim 60^{\circ}}$ represents the critical surface load when the defect is located at $30-60^{\circ}$, $\mathrm{MPa} ; \mu$ represents the defect depth; $P$ is internal pressure, MPa; $a_{1}, a_{2}, a_{3}, a_{4}, a_{5}, a_{6}$, and $a_{7}$ are the coefficients of the equation, as listed in Table 4. 
Table 4. Coefficient of the fitting formula $\left(30-60^{\circ}\right)$.

\begin{tabular}{ccccccc}
\hline $\mathbf{a}_{\mathbf{1}}$ & $\mathbf{a}_{\mathbf{2}}$ & $\mathbf{a}_{\mathbf{3}}$ & $\mathbf{a}_{\mathbf{4}}$ & $\mathbf{a}_{\mathbf{5}}$ & $\mathbf{a}_{\mathbf{6}}$ & $\mathbf{a}_{\mathbf{7}}$ \\
\hline-1.116 & -0.349 & -0.115 & 2.850 & 0.163 & 0.710 & 0.931 \\
\hline
\end{tabular}

A comparison between the predicted and simulation results when the defect was located at $30-60^{\circ}$ is shown in Figure 27. The error of the formula was less than $10 \%$.

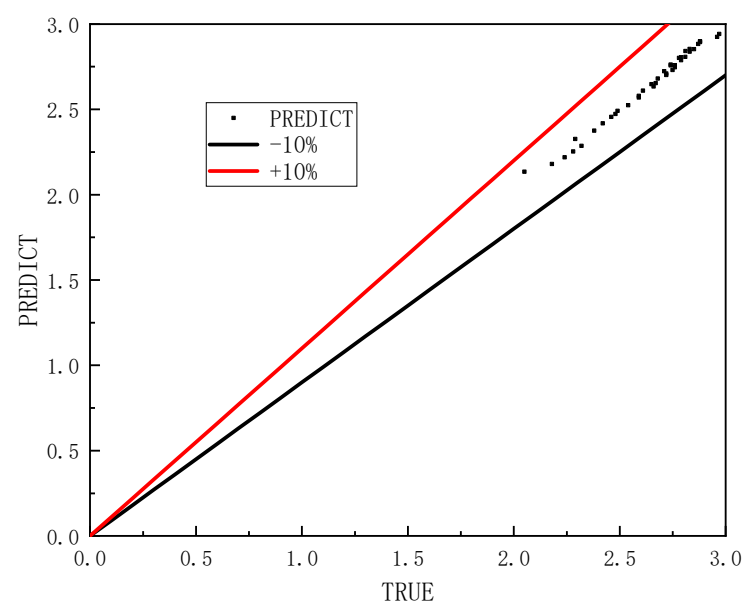

Figure 27. Comparison between predicted and calculated values $\left(30 \sim 60^{\circ}\right)$.

For a defect located at $60-90^{\circ}$, the safety assessment curves of the HDPE pipeline are shown in Figure 28. When the defect depth was small, the failure load of the pipeline changed more gently; when the defect depth was more than $3 \mathrm{~mm}$, the rate of change began to increase, and when the defect depth was large, the variation was smooth. This is because when the defect was located at $90^{\circ}$, the maximum von Mises stress of the pipeline appeared on the left and right sides of the pipeline when the defect depth was relatively shallow. As the defect depth increased, the stress concentration at the defect became more obvious and the maximum Mises stress finally occurred at the defect site.

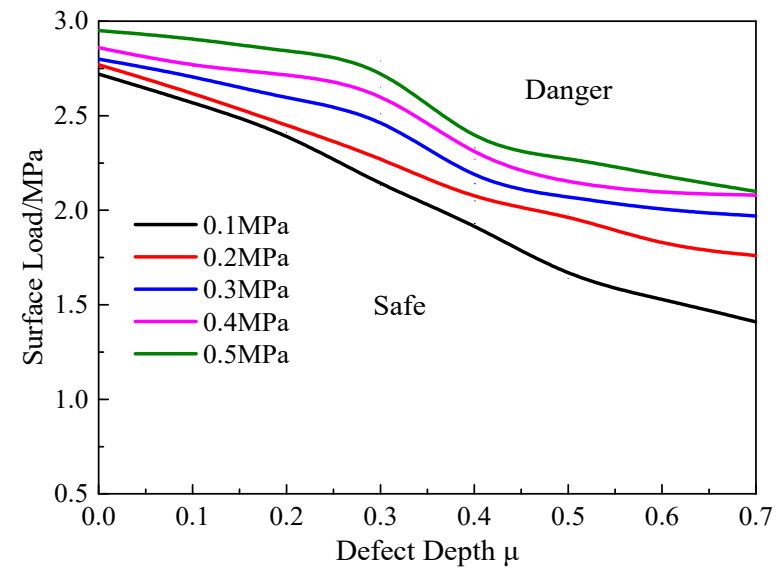

Figure 28. Defect depth-critical surface load curves for different internal pressure loads $\left(60-90^{\circ}\right)$.

Formulae for the ultimate surface load, defect depth, and internal pressure of the pipeline when the defect was located at $60-90^{\circ}$ can be obtained according to the failure evaluation curves. The R-squared value of the correlation coefficient is 0.942 .

$$
S L_{60 \sim 90^{\circ}}=\left(a_{1} \mu^{3}+a_{2} \mu^{2}+a_{3} \mu+a_{4}\right) \cdot\left(a_{5} P^{a_{6}}+a_{7}\right)
$$


Here $S L_{60 \sim 90^{\circ}}$ represents the critical surface load when the defect located at 60-90 , $\mathrm{MPa} ; \mu$ represents the defect depth; $P$ is internal pressure, $\mathrm{MPa} ; a_{1}, a_{2}, a_{3}, a_{4}, a_{5}, a_{6}$ and $a_{7}$ are the coefficients of the equation, as listed in Table 5.

Table 5. Coefficient of the fitting formula $\left(60-90^{\circ}\right)$.

\begin{tabular}{ccccccc}
\hline $\mathbf{a}_{\mathbf{1}}$ & $\mathbf{a}_{\mathbf{2}}$ & $\mathbf{a}_{\mathbf{3}}$ & $\mathbf{a}_{\mathbf{4}}$ & $\mathbf{a}_{\mathbf{5}}$ & $\mathbf{a}_{\mathbf{6}}$ & $\mathbf{a}_{\mathbf{7}}$ \\
\hline 4.845 & -4.871 & -0.040 & 2.292 & 0.614 & 0.566 & 0.919 \\
\hline
\end{tabular}

A comparison between predicted results and simulation results with a defect at $60-90^{\circ}$ as shown in Figure 29. The percentage difference between the results was less than $10 \%$.

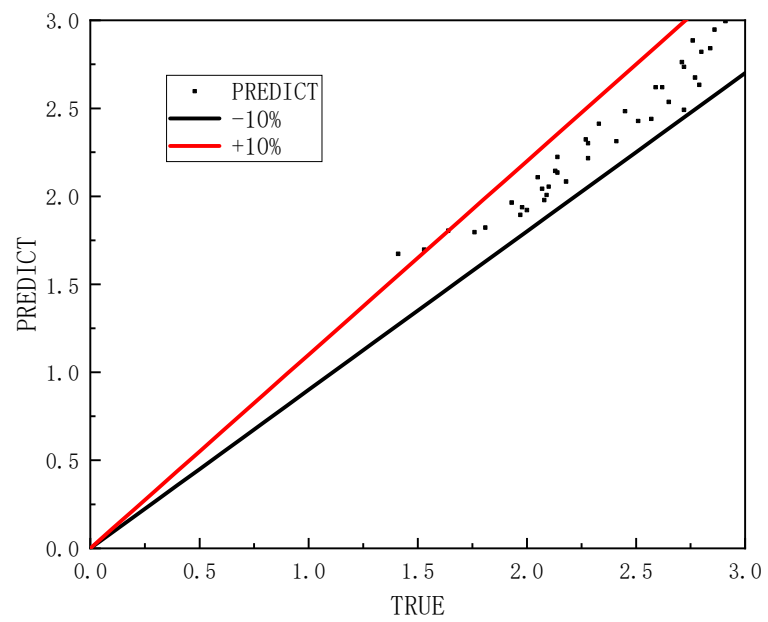

Figure 29. Comparison between predicted and calculated results $\left(60-90^{\circ}\right)$.

\section{Engineering Applications}

A safety evaluation method for gas pipelines with defects is proposed based on the safety evaluation curves and critical surface load calculation, which can be directly referenced in engineering practice, as shown as Figure 30. The steps are as follows:

1. Determine the operating pressure of the gas pipeline with defects.

2. Determine the pipeline defect depth using detection and excavation measures and calculate the ratio of wall thickness to defect depth.

3. According to the location of the defect, select the appropriate pipeline safety assessment curve for defects located in the ranges $\left[0^{\circ}, 30^{\circ}\right],\left[30^{\circ}, 60^{\circ}\right]$ and $\left[60^{\circ}, 90^{\circ}\right]$ and evaluate the safety state of the gas pipeline according to the surface load at the upper end of the pipeline.

4. Repair dangerous sections of the gas pipeline. The proposed safety evaluation method can guide safety management of gas pipelines. 


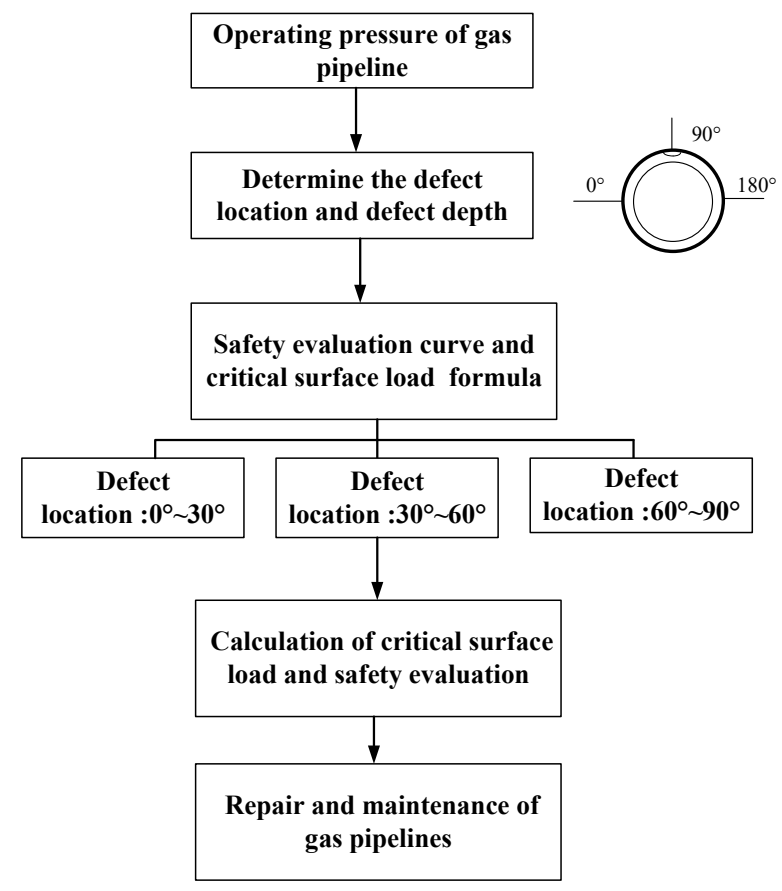

Figure 30. Fitness-for-service assessment method for pipes with defects.

A medium-pressure gas pipeline (PE110) in Zhongmensigou, Yuyuan District, and Mentougou District in Beijing City, which was supplied by the Beijing Huayou United Gas Development Co., Ltd., was damaged by the construction team of Jinhe Water Construction Company, as shown as Figure 31. This gas pipeline was selected to demonstrate a realworld application of the proposed safety evaluation method. The construction process produced a volume defect in the pipeline.
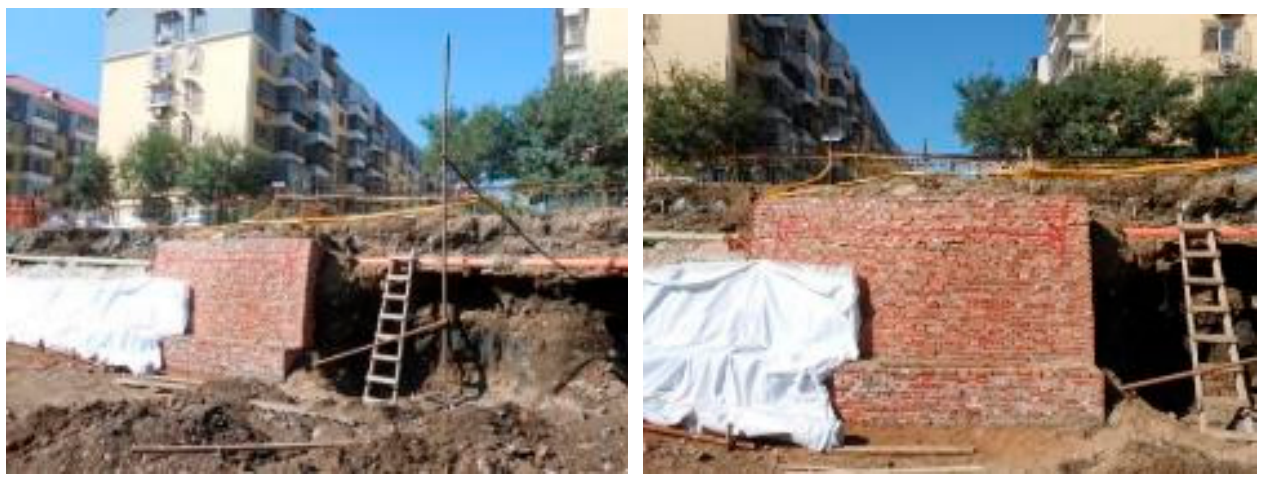

Figure 31. Buried gas pipeline in the city.

The construction process can cause volume defects in the pipeline as illustrated in Figure 32. The pipe diameter was $110 \mathrm{~mm}$, the wall thickness was $10 \mathrm{~mm}$, and the internal pressure was $0.4 \mathrm{MPa}$. The defect depth was measured on site as $5.6 \mathrm{~mm}$. 


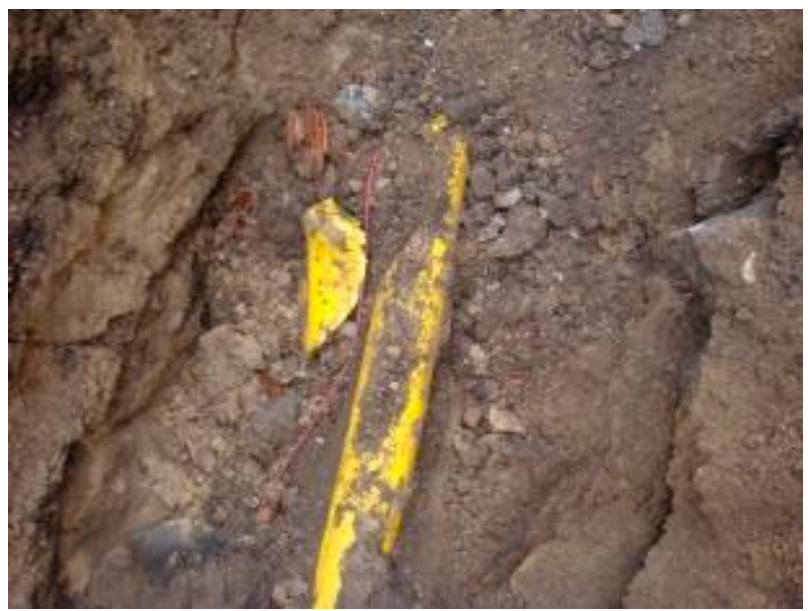

Figure 32. Defect in HDPE pipe.

For defects located at $60-90^{\circ}$, the critical surface load can be calculated using the following formula:

$$
\begin{aligned}
S L_{60 \sim 90^{\circ}} & =\left(4.845 \mu^{3}-4.871 \mu^{2}-0.04 \mu+2.292\right) \cdot\left(0.614 P^{0.566}+0.919\right) \\
& =\left(4.845 \times 0.56^{3}-4.871 \times 0.56^{2}-0.04 \times 0.56+2.292\right) \cdot\left(0.614 \times 0.4^{0.566}+0.919\right) \\
& =2.046 \mathrm{MPa}
\end{aligned}
$$

The critical surface load of pipe is $2.046 \mathrm{MPa}$. The surface load is determined by measuring the pressure around the pipeline. Thus, the pipeline can operate safely in its current state.

\section{Conclusions}

In this study, the mechanical properties and failure characteristics of pipes with defects under surface load were investigated using the finite element method. The influence of defect position, pipeline internal pressure, defect depth, and defect width parameters on the stress response of the pipe were analyzed. The HDPE pipeline safety evaluation curves were obtained for various working conditions. The main conclusions of this work can be summarized as follows:

1. A solid model of a HDPE pipe with defects under surface load was established. The model considers nonlinearity of the pipe material and soil, nonlinear contact between the pipe and soil, and geometric nonlinearity of pipe deformation. Furthermore, the rationality of the model was verified by comparing the simulation results with previously published results for a pipe with no defects.

2. As the surface load increases, the maximum von Mises stress in the HDPE pipe with defects gradually increases and the position of maximum stress shifts from the top and bottom of the pipe to the defect position and the arch line of the pipe. When the von Mises stress exceeds the yield limit, the pipe fails. The load also leads to the pipeline in the pressure area of the large vertical settlement; therefore, the pipeline is more prone to failure.

3. The defect location will affect the failure process of the HDPE pipeline. When the defect is located was $0^{\circ}$, the critical failure load of the pipeline was smallest. The von Mises stress in the pipeline was lowest and the critical failure load was highest when the defect was located at $30^{\circ}$. Under a small surface load, the pressure in the pipe will have the largest influence on the mechanical behavior of the pipeline with defects. In addition, the maximum von Mises stress in the pipe varies with the variation in internal pressure load with increasing surface load. When the maximum von Mises stress in the pipe exceeds the yield limit and expires, the pipe internal pressure will have a minimal impact on the mechanical properties of the pipe. 
4. As the depth of the defect increases, the maximum von Mises stress of the HDPE pipe also gradually increases and the relationship between defect depth and critical failure load decreases linearly. With increasing defect length, the maximum von Mises stress of the pipe gradually increases; however, the length of the defect will have very little effect once the length exceeds $30 \mathrm{~mm}$. The maximum von Mises stress decreases with increasing defect width.

5. Failure assessment curves of the HDPE pipeline were obtained for various surface loads, internal pressure loads, and defect depths. The formula for calculating the critical surface load according to defect parameters was obtained with nonlinear fitting. The proposed assessment method can be used as part of the safety evaluation of HDPE pipes with defects. The results of this study provide important reference for preventing gas pipeline accidents.

Author Contributions: X.L. conceived the analysis. J.L. deduced the analytical model, established the numerical model. H.Z. designed the analysis. B.W. performed the parametric analysis and wrote the paper. D.Z. established the regression model. B.J. performed the parametric analysis. F.F. conducted the field investigation and calculation. All authors have read and agreed to the published version of the manuscript.

Funding: This research has been co-funed by National Science Foundation of China (Grant No. 52004314), Beijing Municipal Natural Science Foundation (Grant No. 8214053), Tianshan Youth Program (Grant No. 2019Q088), the Open Project Program of Beijing Key Laboratory of Pipeline Critical Technology and Equipment for Deepwater Oil \& Gas Development (Grant No. BIPT2020005), Science Foundation of China University of Petroleum, Beijing (No. 2462018YJRC019, No. 2462020YXZZ045).

Institutional Review Board Statement: Not applicable.

Informed Consent Statement: Informed consent was obtained from all subjects involved in the study.

Data Availability Statement: All data have been involved in the paper.

Acknowledgments: Kui Xu from China University of Petroleum-Beijing is acknowledged for his support on the numerical model.

Conflicts of Interest: The authors declare no conflict of interest.

\section{Nomenclature}

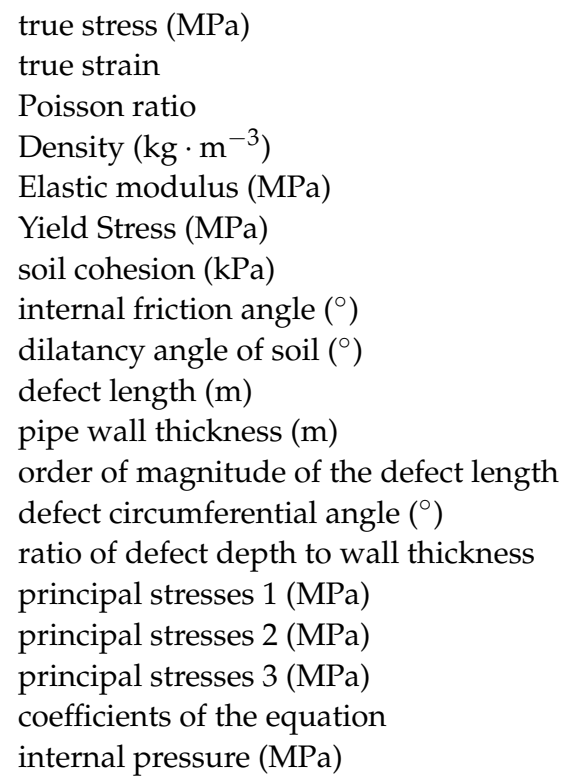




\section{References}

1. Chen, W. The solution of the occupied pipeline in oil field. Oil-Gas Field Surf. Eng. 2012, 31, 70.

2. Wu, S. Nanjing Xiaguan Gas Pipeline Rupture, Suspected due to Heavy Vehicle Overloading Rolling. N/OL. Yangzi Evening News. Available online: http:/ / news.163.com/13/0307/05/8PBFEI4E00014AED.html (accessed on 7 March 2013).

3. Ren, B.; Li, X.P.; Liao, X.; Zhang, K. Analysis on the Safety Hidden Danger of illegal occupation and pressure along the Long Natural gas Pipeline. Technol. Enterp. 2014, 11, 121-127.

4. Li, M.Y.; Chen, G.H. Finite Element Analysis of Buried PE Gas Pipeline under Traffic Load. China Plast. Ind. 2009, $37,30-33$.

5. Zhu, Y. Traction calculation of HDPE pipe with trenchless directional drilling. Water Technol. 2012, 6, 61-64.

6. Huang, L.H.; Xu, Y.F. High density polyethylene HDPE pipeline construction leakage prevention measures. Constr. Sci. Technol. 2016, 10, 130-131.

7. Guo, X.J. The Deformation and Failure Mechanism of HDPE Pipes in Horizontal Directional Drilling back to the Trailer and Numerical Simulation. Master's Thesis, Chengdu University of Technology, Chengdu, China, 2011.

8. Shuai, J.; Wang, X.L.; Ye, Y.X.; Zuo, S.Z. Stress analysis of pipeline subject to surface load. J. China Univ. Pet. $2009,33,99-103$.

9. Li, J.P.; Ding, S.J. Influence of Additional Load Caused by Adjacent Buildings on Underground Pipeline. J. Tongji Univ. $2004,32,1553-1557$.

10. Yang, J.T. Research on longitudinal Mechanical Characteristics of Pipelines Buried in Soft Soil under Vertical Loads. Master's Thesis, Zhejiang University, Hangzhou, China, 2006.

11. Zhang, J.; Liang, Z. Mechanical behavior analysis of a buried steel pipeline underground overload. Eng. Fail. Anal. 2016, 63, 131-145. [CrossRef]

12. Ma, F.S.; Zhao, H.J.; Zhang, Y.M.; Zhao, J.; Wang, J.; Wei, A.H.; Gong, C.C. Numerical Simulation of Gas Pipeline Deformation under Load; Institute of Geology and Geophysics, Chinese Academy of Sciences: Beijing, China, 2011.

13. Han, C.J.; Zhang, H.; Zhang, J.; Li, Q. Analysis on influence of surface load to stress-strain characteristics of pipeline buried in hard rock region. J. Saf. Sci. Technol. 2015, 11, 23-29.

14. Li, J.; Zhang, H.; Wu, K.; Gu, X.T.; Xia, M.Y.; Liu, X.B. Failure behavior analysis on PE gas pipeline under the effect of third-party excavation. J. Saf. Sci. Technol. 2017, 13, 108-116.

15. Zhang, J.; Liang, Z.; Han, C. Numerical Simulation of Pipeline Deformation Caused by Rock fall Impact. J. Sci. World J. 2014, $2014,161898$.

16. Zheng, J.Y.; Lu, S.L.; Ma, J.J.; Shi, J.F. Numerical Simulation of Mechanical Response of Buried Polyethylene Pipes Under Surface Load. China Plast. 2014, 28, 60-64.

17. Ren, J.D.; Wang, W.; Dong, M.; Gao, S. Analysis of deformation and mechanical characteristics of buried pipelines in mining subsidence areas. China Saf. Sci. J. 2020, 30, 86-93.

18. Ma, J.J. Numerical Simulation of Strength of Buried Polyethylene Pipe under Typical Complex Loading. Master Thesis, Zhejiang University, Hangzhou, China, 2013.

19. Liu, P.F.; Zheng, J.Y.; Zhang, B.J.; Shi, P. Failure analysis of natural gas buried X65 steel pipeline under deflection load using finite element method. Mater. Des. 2010, 31, 1384-1391. [CrossRef]

20. Li, M.; Zhang, H.; Wang, B.D.; Liu, X. Failure analysis and safety evaluation on P110 oil tube containing corrosion defects based on finite element method. J. Saf. Sci. Technol. 2016, 12, 93-99.

21. Zhang, J.; Liang, Z.; Han, C.J.; Zhang, H. Buckling behavior analysis of a buried steel pipeline in rock stratum impacted by a rock fall. Eng. Fail. Anal. 2015, 58, 281-294. [CrossRef]

22. Vazouras, P.; Karamanos, S.A.; Dakoulas, P. Finite element analysis of buried steel pipelines under strike-slip fault displacements. Soil Dyn. Earthq. Eng. 2010, 30, 1361-1376. [CrossRef] 